\title{
On Influence of ERP for Enterprise Accounting Finance Management in China
}

\author{
Huang Ying \\ Chengdu Aeronautic Polytechnic \\ Chengdu, Sichuan,China
}

\begin{abstract}
With the constant development of modern society, enterprises are facing increasingly severe competition situation. Thus, improving enterprise operation management level, improving enterprise economic efficiency and enhancing enterprise competitiveness and benefit obtaining ability have become the focus content of enterprise development process at current stage. The appearance of ERP system provides a new idea and environment for enterprise accounting finance management, which effectively improves enterprise operation management level. This paper analyzes and discusses ERP influence on enterprise accounting finance management in China at current new situation.
\end{abstract}

Keywords-ERP; enterprise accounting finance management; influence;

\section{INTRODUCTION}

At present, with the rapid development of social economy level and the intensification of market competition, enterprise must improve its own internal management level, in order to adapt to fierce market competition situation. Especially in the current globalization trend, with rapid development, Chinese enterprises must adopt advanced management mode to improve its own modern management level, in order to obtain a space in the international competition. ERP system is an important means of modern enterprises conducting internal management work. It effectively realizes data unified processing, and introduces advanced information network technology, which effectively conducts scientific configuration and management for enterprise human labor, material strength, financial strength and information resources, simplifying the management process, improving internal management efficiency, in order to better ensure enterprises to obtain a good survival and development ability.

\section{SPECIFIC IDEA CONNOTATION OF ERP SYSTEM}

First of all, ERP system realizes enterprises' control and management for supply chain, and it can conduct effective implementation for various business processes, in order to help enterprise better adapt to external market competition environment change, realizing unified management for enterprises' internal fund, information and products. Especially the combination of financial management and EPR system can better improve the circulation efficiency of information in financial management, improving the information integrity and timeliness, and it can find and solve the problems in daily operation management of enterprises for the first time.

Second, ERP system realizes agile, lean and synchronization of enterprise production process. With rapid change of market, enterprises must constantly adapt to market demand to make internal adjustment, agile thinking of production process refers to that, enterprises control and adjust internal supply chain, making rapid reaction for market demand, in order to ensure enterprise products to have strong flexibility and diversity. Synchronization is the combination of enterprise and supply chain. Through concurrent engineering theory, it maintains the synchronization of enterprise production development and market change, in order to ensure the long-term enterprise operation. Lean is mainly in ERP thinking, and enterprises conduct unified management of suppliers, agents, distributors and relevant cooperation enterprises, constructing a set of lean survival system, which can effectively improve product quality.

Finally, ERP system can effectively realize control of the whole process for enterprise finance management process. Pre-plan and medium plan are the key content of financial management work. Through the ERP system application, through transaction processing, it can make automatic storage for relevant accounting checking recording, thus effectively improving accounting checking work efficiency and reducing the problem of manual operation error rate.

\section{ERP INFLUENCE ON ENTERPRISE ACCOUNTING}

\section{FINANCE MANAGEMENT IN CHINA}

\subsection{From Local Perspective, EPR Influence on Enterprise Accounting Finance Management in China.}

EPR system is applied in financial accounting work. Through traditional accounting calculation, recording and fund analysis to re-define, it ensures the supervision level of enterprise economic activities, and it also obtains effective guarantee of enterprise general ledger, cash, fixed assets, accounts payable and receivable management level. ERP management system generally has complete management module, which can make unified control and management of enterprise fund, fixed assets, and accounting and total account modules. ERP management system is applied in financial accounting work. Through rational analysis, it 
realizes the control of enterprise cost level, and predicts enterprises' economic activity results. Through financial plans and analysis control, it effectively ensures pre, medium and post control and feedback effect. EPR financial management module integration for financial management process realizes integrated management module, and compared with traditional accounting process, it is more effective, quick and convenient. At the same time, with the constant development of modern social globalization economic trend, enterprises' internal branch department uses ERP management system can effectively realize financial management unification, and it ensures the operation efficiency of enterprise financial management work, reducing enterprise operation human labor.

In ERP system, it has a unified cost management data management module, and it has simple operation, which can conduct whole process monitoring of enterprise cost and income, and conduct monitoring of different departments. In enterprise operation process, one it has management problem, it can use ERP system to react specific problem root, and solve it the first time. ERP management system has strong timeliness, integrity and prospect. ERP system can conduct linkage analysis and processing of relevant materials, realizing real-time update of enterprises' internal information. It improves flow efficiency of internal consulting in enterprise, in order to better improve enterprise competitiveness and provides corresponding control basis for enterprise decisions.

ERP system application has a profound influence on accounting staff role and positioning. ERP system application alleviates the material recording limitation of accounting staff, and it realizes automatic recording of different departments, realizing accounting automatic recording and production, and it automatically produces relevant reports, and the traditional basic work of accounting staff will be gradually replaced. The work focus of accounting personnel has changed, and work responsibility will also change. ERP system application needs to obtain a good implementation effect, and accounting staff must do well the role positioning and the work transfer, in order to better highlight ERP system application's specific advantages. Accounting personnel need to make deep processing of accounting information, and it analyzes existing problems of enterprise operation management according to reports and relevant data of ERP system. And it proposes methods of effectively improving enterprise performance management level, which better contributes the actual strength of enterprise accounting. ERP system's constant application and financial management work application make improvement of traditional accounting work mode and work flow, and accounting personnel must recognize the change form of current stage.

\subsection{From Overall Perspective, ERP Influence on Enterprise Accounting Finance Management in China}

From overall perspective, ERP system is applied in enterprise accounting finance management work, which can effectively improve the defects of previous accounting management work and better realize the financial information management support in the whole process. Traditional financial management work mainly focuses on relevant data collection of post management, which is hard to ensure its management decision material real-time and target, and the overall information quality is not high, influencing the follow-up decision and management work effect. ERP system application will realize automatic operation process, which effectively improves financial management level.

ERP system application will weaken the features of traditional financial management work, and emphasizes financial management features and demand. Financial management staff are no longer responsible for sales cost and income accounting and confirmation, and through other business department inputting relevant sales data, ERP system will automatically make plans, and automatically make purchase plan arrangement. Production department will survive according to ERP system output production plan. A series of steps will automatically complete through ERP system, liberating the hands of financial management staff and also reducing the error and other infections, in order to ensure the overall business process of enterprise simplified and standardized, improving the unifying of financial information. Business operation requirement of financial management staff reduces, and people can focus on enterprise financial management work. It can have profound management of enterprise purchase, cost control and accounts receivable, improving enterprise financial management level and operation effect.

ERP system application can effectively improve the management effect of enterprise finance and realizes standard financial management. ERP system application can realize more accurate and timely profit prediction and contract management, and automatically complete sales contract pricing calculation. According to contract price change, it can make accurate calculation of income, profit and cost, effectively realizing the goal of providing relevant data for enterprise decision-maker. Relevant sales department can be unlimited by space and time, and through ERP system for online evaluation, it effectively reduces evaluation time. Also, ERP system can make real-time control and analysis of overall financial budget management work, and it makes detailed checking of different fee details. Through different modes of checking and management, it can make better control and management of company daily operation cost. ERP system can make scientific statistics and calculation of overall management fee, and it can provide a good method for product survey cost demand analysis, to ensure the profitability control and grasp of enterprise. Through ERP 
system application, it makes unified control of enterprise profit and cost, and makes comparison of enterprise income and detailed budget, analyzing deviation reason, in order to better control the financial budget implementation result, realizing the supervision and management of the whole process. ERP system application, on the other hand, improves enterprise management level for its assets, and also improves internal resource usage efficiency of enterprise. ERP system makes detailed management of assets transfer, purchase, organization and processing business process, and through electronic assets card and other high efficiency management form application, it can effectively improve business detail processing ability, improving management and control level of different enterprise assets.

\section{CONCLUSION}

In a word, with the constant development of modern science and technology, ERP system is also constantly improving. With ERP system's constant deep application, enterprise finance management work in China also makes great changes. Enterprise managers should actively recognize the ERP influence on enterprise accounting finance management work, and constantly positively strengthen relevant system construction, in order to better promote ERP system application and implementation and improve enterprise development level.

\section{REFERENCES}

[1] Yin Jun. Analysis on ERP influence on enterprise accounting finance management in China[J]. Modern Economy Information. 2011(20).

[2] Fu Qinghe. ERP system influence on enterprise accounting and financial management[J]Enterprise Herald. 2010(11).

[3] Li Yongdong. Study on ERP system application in enterprise accounting and financial management[J]. Value Project. 2010(20)

[4] Chen Ruixue. Analysis on knowledge economy influence on enterprise finance management[J]. Shopping Mall Modernization. 2010 (32)

[5] Zhang Wei. Influence of treasury centralized payment system on university finance management $[\mathrm{J}]$. Contemporary Economy. 2011(20)

[6] Ma Yong. From accounting computerization to finance management in ERP system[J]. Financial Field (Academic Edition). 2011(09). 